\title{
Effect of clomifene citrate plus metformin and clomifene citrate plus placebo on induction of ovulation in women with newly diagnosed polycystic ovary syndrome: randomised double blind clinical trial
}

\author{
Etelka Moll, Patrick M M Bossuyt, Johanna C Korevaar, Cornelis B Lambalk, Fulco van der Veen
}

\begin{abstract}
Objective To compare the effectiveness of clomifene citrate plus metformin and clomifene citrate plus placebo in women with newly diagnosed polycystic ovary syndrome.

Design Randomised clinical trial.

Setting Multicentre trial in 20 Dutch hospitals.

Participants 228 women with polycystic ovary syndrome. Interventions Clomifene citrate plus metformin or clomifene citrate plus placebo.

Main outcome measure The primary outcome measure was ovulation. Secondary outcome measures were ongoing pregnancy, spontaneous abortion, and clomifene resistance. Results 111 women were allocated to clomifene citrate plus metformin (metformin group) and 114 women were allocated to clomifene citrate plus placebo (placebo group). The ovulation rate in the metformin group was $64 \%$ compared with $72 \%$ in the placebo group, a non-significant difference (risk difference $-8 \%, 95 \%$ confidence interval $-20 \%$ to $4 \%$ ). There were no significant differences in either rate of ongoing pregnancy $(40 \% v 46 \% ;-6 \%,-20 \%$ to $7 \%$ ) or rate of spontaneous abortion (12\% v 11\%; $1 \%,-7 \%$ to $10 \%)$. A significantly larger proportion of women in the metformin group discontinued treatment because of side effects $(16 \% v$ $5 \% ; 11 \%, 5 \%$ to $16 \%$ ).

Conclusion Metformin is not an effective addition to clomifene citrate as the primary method of inducing ovulation in women with polycystic ovary syndrome.

Trial registration Current Controlled Trials ISRCTN55906981 [controlled-trials.com].
\end{abstract}

\section{Introduction}

Polycystic ovary syndrome is characterised by any of oligoanovulation, clinical or biochemical hyperandrogenism, and polycystic ovaries. $^{12}$ The syndrome affects around 4-9\% of women of reproductive age. ${ }^{3}$ Women most commonly seek counselling or treatment because of infertility due to chronic anovulation. Insulin resistance accompanied by compensatory hyperinsulinaemia constitutes another major biochemical feature of polycystic ovary syndrome, which leads to early luteinising hormone sensitivity of the follicle and to stimulation of both ovarian and adrenal androgen production. ${ }^{4-8}$

The first choice drug in women with newly diagnosed polycystic ovary syndrome is the antioestrogen clomifene citrate. ${ }^{9}$ Clomifene citrate enhances release of pituitary gonadotrophins, resulting in follicular recruitment. Three quarters of women with polycystic ovary syndrome will ovulate with clomifene citrate. ${ }^{10}$ Complications of treatment are rare and usually mild. Patients who do not ovulate on the maximum dose of $150 \mathrm{mg}$ are considered to be clomifene citrate resistant.

Recently, the addition of metformin, an insulin sensitiser, to clomifene citrate has been proposed as an alternative first line treatment option for women with polycystic ovary syndrome. Insulin sensitisers improve hyperinsulinaemia and hyperandrogenism in these women. ${ }^{11}{ }^{12}$ One study also showed that metformin regulated menstrual cycles and pregnancies. ${ }^{12} 13$

Metformin is now the most widely used insulin sensitiser for induction of ovulation in women with polycystic ovary syndrome and may improve ovulation rates when combined with clomifene citrate in clomifene citrate resistant women. ${ }^{14}$ This has led to the recommendation to use metformin alone or in combination with clomifene citrate as first line treatment in infertile women with polycystic ovary syndrome.

As clomifene citrate is an effective treatment, ${ }^{10}$ however, what are the added benefits of metformin? Two randomised controlled trials have examined this question. One small study found a significant increase in ovulation rates, ${ }^{14}$ while a larger study failed to find a significant difference. ${ }^{15}$ Sample sizes of both studies were small, performance was not double blinded, and previous treatment of the participants was unclear.

We determined whether a strategy of adding metformin to the standard treatment with clomifene citrate results in a higher ovulation rate, higher pregnancy rate, and less clomifene citrate resistance in a randomised clinical trial among women with newly diagnosed polycystic ovary syndrome.

\section{Methods}

Participants and experimental protocol

From June 2001 to May 2004 we invited relevant women from 20 Dutch hospitals to participate in the trial. All women had chronic anovulation (menstrual cycle $\geq 35$ days, WHO type II, normogonadotropic, normo-oestrogenic, oligoanovulation or anovulation) and polycystic ovaries diagnosed by transvaginal ultrasonography and wanted to conceive.

We defined polycystic ovary syndrome according to current guidelines. ${ }^{1}$ We excluded women with other causes of anovulation, age $>40$ years, and liver, kidney, or heart disease or failure (that is, abnormal results on liver function tests or serum creatinine concentration $>95 \mu \mathrm{mol} / \mathrm{l}$ or a history of heart disease or failure) and also those whose partner's sperm quality indicated male factor subfertility (total motile count $<10 \times 10^{6}$ ). Tubal patency was not tested before induction of ovulation. 


\section{Research}

Women who gave informed consent were randomly allocated to clomifene citrate plus metformin (metformin group) or clomifene citrate plus placebo (placebo group). Randomisation was done in the coordinating centre (AMC, Amsterdam) by using computer generated blocks of four. Merck Santé, France, prepared the containers with the study medication. They determined the final allocation sequence and kept this list until inclusion was finished. The randomisation was stratified per centre, and the centres received blinded, numbered containers with medication. Each participant received the container with the next number in her own hospital.

We tested liver and kidney function before women started taking the study medication. The dose was increased from one to four tablets a day (that is, up to $2000 \mathrm{mg}$ ) over a period of seven days. ${ }^{16}$ We used this "step up" regimen to limit side effects. Patients continued to take the study medication until they had a positive pregnancy test or six ovulatory cycles or developed clomifene citrate resistance, whichever came first.

Women took metformin or placebo for one month, to allow metformin enough time to have a sufficient insulin sensitising effect. ${ }^{14}$ If no spontaneous menstruation occurred and the pregnancy test was negative one month after the study medication was started, we induced menstruation with dydrogesterone 10 $\mathrm{mg}$ three times a day for 10 days. From the third or fifth day until the seventh or ninth day after (spontaneous or induced) menstruation, women took $50 \mathrm{mg}$ clomifene citrate a day. If ovulation did not occur with this dose, it was increased with steps of $50 \mathrm{mg}$ to a maximum of $150 \mathrm{mg}$ a day in the next cycles. Ovulation was detected either with a biphasic basal temperature curve, a follicle with a diameter $\geq 16 \mathrm{~mm}$ on transvaginal ultrasonography, or progesterone $\geq 14 \mathrm{nmol} / \mathrm{l}$ in the second half of a menstrual cycle, or pregnancy. If a woman ovulated, she continued taking the same dose of clomifene citrate until an end point was reached.

If women had an ovulatory cycle with a certain dose of clomifene citrate followed by a cycle without ovulation at the same dose, they were classified as temporarily ovulatory. These women entered the next cycle with a higher dose of clomifene citrate.

\section{Statistical analysis}

The primary outcome measure was ovulation. Secondary outcome measures were ongoing pregnancy, spontaneous abortion, and clomifene resistance. We compared the cumulative rates of ovulation as well as other rates and proportions between groups using relative rates, rates differences, and $\chi^{2}$ test statistics using SPSS 11.5.1.

With an expected rate of ovulation of $75 \%$ in the placebo group ${ }^{10}{ }^{17}$ we needed 200 women to show an absolute increase of $15 \%$ in ovulation rate, with a power of at least $80 \%$ using a two sided $\chi^{2}$ test with a $5 \%$ significance level.

\section{Results}

We screened 228 women for eligibility. Three had to be excluded: two had type 2 diabetes and one had raised liver enzyme activity. Baseline characteristics were similar in the two groups apart from the mean total motile sperm count in partners (table 1).

In the 111 women allocated to metformin, six became pregnant and five dropped out before they started taking the study medication (fig 1). Eighty women received $50 \mathrm{mg}$ clomifene citrate, of whom 44 went on to take $100 \mathrm{mg}$ clomifene citrate, and 17 eventually took $150 \mathrm{mg}$. Twelve women developed resistance to clomifene citrate.
Table 1 Baseline characteristics of women in study according to allocation to clomifene citrate plus metformin or clomifene citrate plus placebo. Figures are numbers (percentages) of women unless stated otherwise

\begin{tabular}{lcc} 
Characteristics & $\begin{array}{c}\text { Clomifene citrate }+ \\
\text { metformin }(\mathbf{n}=111)\end{array}$ & $\begin{array}{c}\text { Clomifene citrate }+ \\
\text { placebo }(\mathbf{n}=114)\end{array}$ \\
\hline Mean (SD) age (years) & $27.9(3.7)$ & $28.4(4.7)$ \\
\hline Parity: & $89(80)$ & $95(84)$ \\
\hline Nulliparous & $22(20)$ & $18(16)$ \\
\hline Multiparous & $1.6(1.2)$ & $1.3(1.1)$ \\
\hline Mean (SD) duration of trying to conceive (years) & $28.5(7.1)$ & $27.8(6.7)$ \\
\hline Mean (SD) BMI (kg/m2) & $59 / 104(57)$ & $60 / 109(55)$ \\
\hline BMI $\geq 25$ & $0.82(0.1)$ & $0.83(0.1)$ \\
\hline Mean (SD) waist:hip ratio & $1.92(1.27)$ & $2.13(1.37)$ \\
\hline Mean (SD) LH:FSH ratio & $3.49(3.68)$ & $3.55(3.54)$ \\
\hline Mean (SD) testosterone (nmol/l) & $37(33)$ & $35(31)$ \\
\hline Testosterone concentration $\geq 4 \mathrm{nmol} / \mathrm{l}$ & $12.90(17.95)$ & $11.74(11.89)$ \\
\hline Mean (SD) free androgen index & $33 / 70(47)$ & $35 / 69(51)$ \\
\hline Free androgen index $\geq 8$ & $9.1(6.1)$ & $10.1(4.9)$ \\
\hline Mean (SD) volume of ovaries (ml) & $19 / 70(27)$ & $26 / 65(40)$ \\
\hline Ovary volume $\geq 10 \mathrm{ml}$ & $134(223)$ & $222(370)$ \\
\hline Mean (SD) total motile sperm count $(\times 106)$ & $4.6(8.3)$ & $3.8(4.6)$ \\
\hline Homeostasis model assessment (HOMA) &
\end{tabular}

BMI=body mass index; LH:FSH=luteinising hormone:follicle stimulating hormone.

In the 114 women allocated to the placebo group, four became pregnant and nine dropped out before they started taking the study medication. Ninety two women received $50 \mathrm{mg}$ clomifene citrate, of whom 54 went on to take $100 \mathrm{mg}$ clomifene citrate, and 23 eventually took $150 \mathrm{mg}$. Thirteen women developed resistance. In both groups none of the cycles was cancelled and no one developed ovarian hyperstimulation syndrome.

Cumulative rates of ovulation were slightly lower in the metformin group, but this difference was not significant, nor were differences in cumulative pregnancy and spontaneous abortion rates (table 2). There were no significant differences between the two groups when we analysed the data by clomifene citrate dose (table 3).

In the metformin group, 28 women stopped treatment before reaching an end point. Eighteen stopped because of side effects, 10 because of other or unspecified reasons.

In the placebo group, 21 women stopped treatment before reaching an end point. Six stopped because of side effects, 10 because of other or unspecified reasons, and five had a concomitant disease that prevented continuation of the study.

There was a significant difference between the metformin and placebo group in the discontinuation because of side effects (16\% v 5\%; risk difference $11 \%, 95 \%$ confidence interval $5 \%$ to $16 \%)$.

As 63 women discontinued study medication, 78 and 84 remained for the per protocol analyses. The results in those who did not withdraw showed no benefit with metformin (table 4).

By the end of follow-up, there were 21 live births without complications in the metformin group, 13 spontaneous abortions, and 14 ongoing singleton pregnancies. There were three premature deliveries (gestational age $36+0,33+1$, and $17+5$ weeks). The last pregnancy concerned triplets; none of whom survived. One women developed gestational diabetes but she delivered without further complications. Four women developed hypertension; three delivered without complications, one had a child with Kartagener's syndrome and hypospadias. One woman developed pre-eclampsia and delivered prematurely $(32+6$ weeks). The child had anal atresia.

In the placebo group there were 30 live births without complications, 1 live twin birth without complications, 12 
Table 2 Rates of ovulation, pregnancy, and spontaneous abortion. Figures are numbers (percentages) of women in each group

\begin{tabular}{lcccc} 
& $\begin{array}{c}\text { Clomifene } \\
\text { citrate }+ \\
\text { metformin } \\
\mathbf{( n = 1 1 1 )}\end{array}$ & $\begin{array}{c}\text { Clomifene } \\
\text { citrate }+ \\
\text { placebo }(\mathbf{n}=\mathbf{1 1 4})\end{array}$ & $\begin{array}{c}\text { Risk difference } \\
\%(\mathbf{9 5 \%} \mathbf{~ C l})\end{array}$ & $\begin{array}{c}\text { Relative risk } \\
\mathbf{( 9 5 \% ~} \mathbf{~ C l})\end{array}$ \\
\hline Ovulation & $71(64)$ & $82(72)$ & $-8(-20$ to 4$)$ & $\begin{array}{c}0.89 \\
(0.7 \text { to } 1.1)\end{array}$ \\
\hline $\begin{array}{l}\text { Ongoing } \\
\text { pregnancy }\end{array}$ & $44(40)$ & $52(46)$ & $-6(-20$ to 7$)$ & $\begin{array}{c}0.87 \\
(0.6 \text { to } 1.2)\end{array}$ \\
\hline $\begin{array}{l}\text { Spontaneous } \\
\text { abortion }\end{array}$ & $13(12)$ & $12(11)$ & $1(-7$ to 10$)$ & $\begin{array}{c}1.11 \\
(0.5 \text { to } 2.3)\end{array}$ \\
\hline
\end{tabular}

spontaneous abortions, 9 ongoing singleton pregnancies, and 2 ongoing twin pregnancies. There was one case of intrauterine growth retardation and two premature deliveries $(34+1$ and $18+0$ weeks). The last delivery concerned an anencephalic child who did not survive. Two women developed gestational diabetes and two developed hypertension, all four delivered without further complications. Three women developed pre-eclampsia; two delivered without complications, one delivered prematurely (36+0 weeks).
Table 3 Ovulation per dose of clomifene citrate. Figures are numbers (percentages) of women who ovulated out of the total number of women

\begin{tabular}{lccc} 
Dose & $\begin{array}{c}\text { Clomifene citrate }+ \\
\text { metformin }\end{array}$ & $\begin{array}{c}\text { Clomifene citrate }+ \\
\text { placebo }\end{array}$ & P value \\
\hline $50 \mathrm{mg}$ & $49 / 80(61)$ & $50 / 92(54)$ & 0.36 \\
\hline $100 \mathrm{mg}$ & $27 / 44(61)$ & $35 / 53(66)$ & 0.63 \\
\hline $150 \mathrm{mg}$ & $8 / 17(47)$ & $13 / 23(57)$ & 0.55 \\
\hline
\end{tabular}

There were no significant differences in complications of pregnancy, gestational age, complications of delivery, birth weights, or congenital malformations between the two groups. The power for these comparisons, however, was low.

\section{Discussion}

In the treatment of women with polycystic ovary syndrome who want to get pregnant we could not find any benefit of adding metformin to the standard treatment with clomifene citrate. We found no significant differences in outcome and can exclude any substantial improvement in rates of ovulation and ongoing preg-

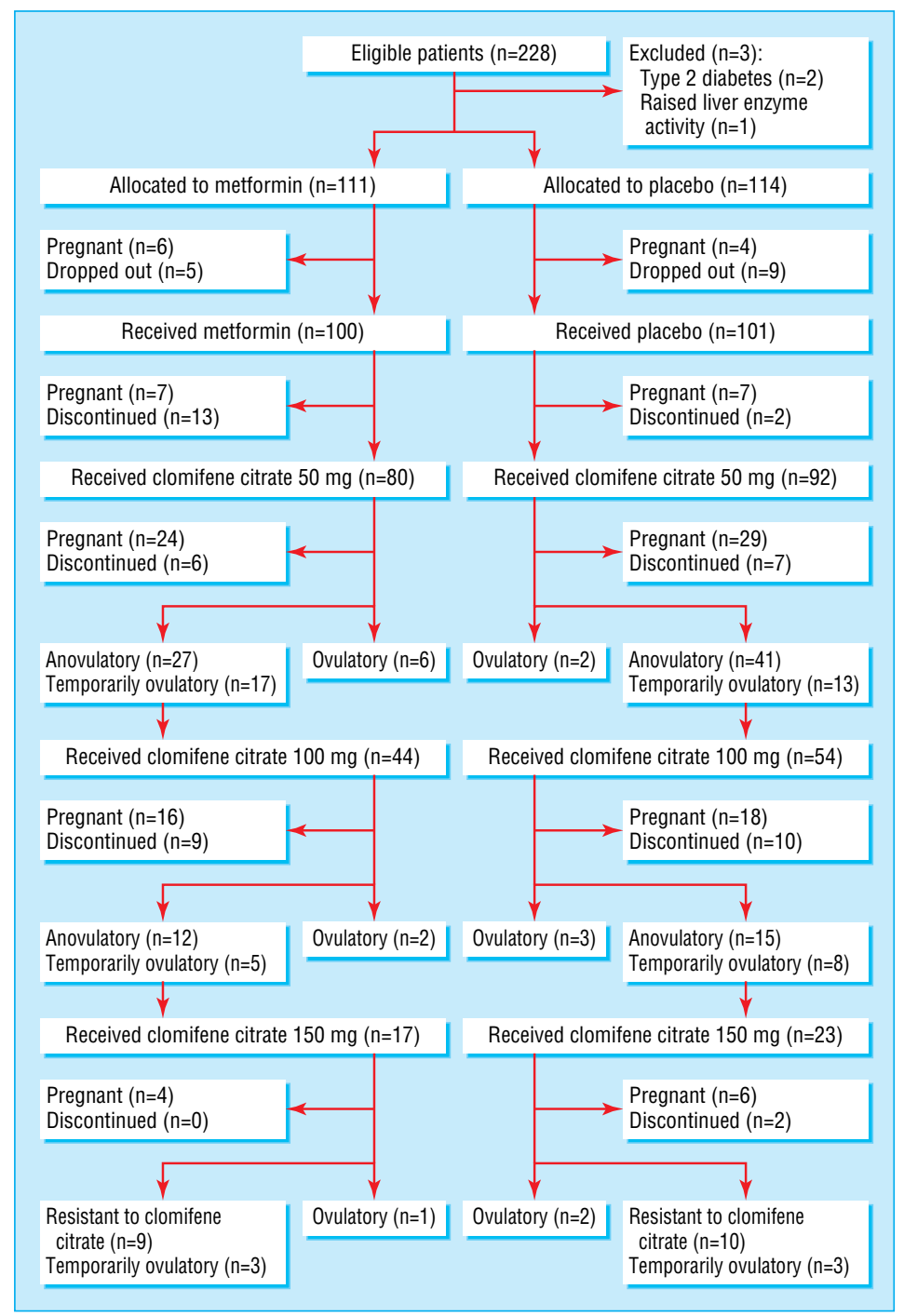

Fig 1 Overview of the clinical trial. Women shown as receiving 50 or $100 \mathrm{mg}$ clomifene citrate received one to six cycles at the noted dose. Ovulatory=women with six ovulatory cycles in total, without pregnancy; temporarily ovulatory=women who ovulated on a certain dose of clomifene citrate at one point in the study and were anovulatory on the same dose at another point in the study. They were treated with a higher dose in the next dose 
Table 4 Rates of ovulation, pregnancy, and spontaneous abortion (per protocol analysis). Figures are numbers (percentages) of women

\begin{tabular}{lcccc} 
& $\begin{array}{c}\text { Clomifene } \\
\text { citrate }+ \\
\text { metformin } \\
(\mathbf{n}=\mathbf{7 8})\end{array}$ & $\begin{array}{c}\text { Clomifene } \\
\text { citrate }+ \\
\text { placebo }(\mathbf{n}=\mathbf{8 4})\end{array}$ & $\begin{array}{c}\text { Risk difference } \\
\mathbf{\%}(\mathbf{9 5 \%} \mathbf{~ C l})\end{array}$ & $\begin{array}{c}\text { Relative risk } \\
\mathbf{( 9 5 \% ~ C l )}\end{array}$ \\
\hline Ovulation & $61(78 \%)$ & $68(81 \%)$ & $-3(-15$ to 10$)$ & $\begin{array}{c}0.97 \\
(0.8 \text { to } 1.1)\end{array}$ \\
\hline $\begin{array}{c}\text { Ongoing } \\
\text { pregnancy }\end{array}$ & $44(56 \%)$ & $51(61 \%)$ & $-4(-19$ to 11$)$ & $\begin{array}{c}0.93 \\
(0.7 \text { to } 1.2)\end{array}$ \\
\hline $\begin{array}{c}\text { Spontaneous } \\
\text { abortion }\end{array}$ & $13(17 \%)$ & $12(14 \%)$ & $2(-9$ to 14$)$ & $\begin{array}{c}1.17 \\
(0.6 \text { to } 2.4)\end{array}$ \\
\hline
\end{tabular}

nancy. Significantly more women in the metformin group discontinued treatment because of side effects.

Patients-We included women with polycystic ovary syndrome, defined according to the 2003 consensus, ${ }^{1}$ who had never used clomifene citrate before and were seeking treatment for their fertility problems for the first time. We evaluated eligibility irrespective of their body mass index. By using these criteria our study group reflects the largest group of women with polycystic ovary syndrome a fertility clinic will see and treat.

Ovulation-Metformin monotherapy induces ovulation through its insulin sensitising effect. In our study, however, we failed to find an increase in ovulation rate of combined therapy compared with clomifene citrate alone. The effects of metformin on ovulation may not be sufficiently strong to improve on the already high ovulation rates with clomifene citrate in these women. This theory is strengthened by the fact that insulin resistance did not improve substantially. It is possible that those women who ovulate on metformin monotherapy would also ovulate on clomifene citrate monotherapy, explaining the absence of an added effect. Our participants were less obese than women in previous studies. Our group represents a normal range of women with polycystic ovary syndrome. Around $35-60 \%$ of women with polycystic ovary syndrome are overweight. Nevertheless, lean women are less likely to benefit from insulin sensitisers because they are less insulin resistant.

Dropouts-The number of dropouts in the metformin group was relatively high in the first month of use. Previous studies have shown that it is not uncommon for patients to experience side effects but that these wear off after a certain time. ${ }^{18}$ There were no differences in baseline characteristics between the women who dropped out and those who completed the study (data not shown). Previous studies have not reported any dropouts. ${ }^{15}$

Comparison-Our findings confirm those of El-Biely and Habba $^{15}$ but conflict with those of Nestler et al. ${ }^{14}$ This discrepancy may in part be caused by a difference in participants. The mean body mass index was lower in our participants $(28 v 32)$ and more were hyperandrogenic (free androgen index $12 v 3$ ) than in the Nestler study. Our participants were more representative of women with polycystic ovary syndrome in Europe.

Schedule-Previous studies have evaluated one menstrual cycle only ${ }^{14}$ or included patients for six months, ${ }^{15}$ whereas our study evaluated six ovulations or lasted until clomifene citrate resistance developed. We think this is a more realistic strategy from a clinical point of view. The downside of this strategy may have been the unexpectedly high rate of women dropping out. As we did not account for this in the power calculation, the power to detect smaller differences has been attenuated. Nevertheless, ovulation rates were lower in the metformin group, and the confidence intervals exclude substantial gains in ovulation and pregnancy rates from adding metformin.

Spontaneous abortion-Some authors have reported that metformin can decrease the rate of spontaneous abortion in women with polycystic ovary syndrome. ${ }^{19-21}$ In our study the rate was similar in both groups and comparable with the rate in the general population. ${ }^{22-24}$ There was no evidence of any protective effect against spontaneous abortion in the metformin group, though this study was not powered for this question. Women had to discontinue their medication as soon as they had a positive pregnancy test as the safety and benefit of using metformin during pregnancy have not yet been proved. This might partially explain why the proportion of miscarriages was equal between the groups.

\section{Conclusion}

Based on the results of this trial, we cannot exclude the possibility that addition of metformin may lead to an increase in the ovulation rate of up to $5 \%$, though whether such a small difference is clinically relevant is doubtful. Though metformin seems to be a relatively safe medication, it is associated with a high incidence of side effects. ${ }^{18}$ We conclude that metformin should not be added to clomifene citrate as primary method for induction of ovulation in women with polycystic ovary syndrome.

We thank the following participants for including and treating patients in this study: R E Bernardus (Ziekenhuis Gooi Noord, Blaricum); H E Bobeck (Rode Kruis Ziekenhuis, Beverwijk); D D M Braat, W N P Willemsen (Universitair Medisch Centrum, Sint Radboud, Nijmegen); J W Briët (Deventer Ziekenhuis, Deventer); J Dawson, I van der Laar (Sint Lucas Ziekenhuis, Amsterdam); H J H M van Dessel, T J G Griffioen (Twee Steden Ziekenhuis, Tilburg); J P R Doornbos (Zaans Medisch Centrum, De Heel, Zaandam); JJ Duvekot, H Versendaal (Medisch Centrum Rijnmond Zuid, Rotterdam); M H Emanuel (Spaarne Ziekenhuis, Haarlem); P A Flierman, H Verhoeve (Onze Lieve Vrouwe Gasthuis, Amsterdam); D A Gietelink, A M Bongers (Amphia Ziekenhuis, Breda); M H A van Hooff (Sint Franciscus Gasthuis, Rotterdam); P W H Houben (Gemini Ziekenhuis, Den Helder); Y M van Kasteren, R Weselius (Medisch Centrum Alkmaar, Alkmaar); C B Lambalk, JJ M L Dekker (Vrije Universiteit Medisch Centrum, Amsterdam); S van der Meer, C van Bolhuis (Medisch Centrum Haaglanden, Den Haag); A W J Omtzigt, $\mathrm{P}$ van Berlo (Flevoziekenhuis, Almere); C N M Renckens (Westfries Gasthuis, Hoorn); E Scheenjes (Ziekenhuis Gelderse Vallei, Ede); M A H M Wiegerinck, P Maas-van Son, B W Mol (Maxima Medisch Centrum, Veldhoven). We thank Nathalie Cugnardey, Merck Santé, France, and Louis $\mathrm{L} M$ van de Ven, Merck, Netherlands.

Contributors: EM conducted the trial and wrote the manuscript. PMMB supervised the progression of the study and reviewed the manuscript. JCK did the statistical analysis and reviewed the manuscript. CBL recruited patients and reviewed the manuscript. FvdV was involved in study design and setting up, reviewed the manuscript, and is guarantor.

Funding: Merck Santé France provided the metformin and placebo. No other funding was received.

Competing interests: None declared.

Ethical approval: The study was approved by the institutional review boards of all hospitals.

\section{What is already known on this topic?}

Three quarters of women with polycystic ovary syndrome ovulate on clomifene citrate alone

In women who are resistant to clomifene citrate alone, addition of metformin may increase ovulation

\section{What this study adds}

Metformin does not increase the number of ovulations or pregnancies when added to clomifene citrate as first line treatment in infertile women with polycystic ovary syndrome

Fifteen percent of women stopped taking metformin because of side effects 
1 Fauser BC, The Rotterdam ESHRE/ASRM-sponsored PCOS consensus workshop group. Revised 2003 consensus on diagnostic criteria and long-term health risk related to polycystic ovary syndrome (PCOS). Hum Reprod 2004;19:1-7.

2 Franks S. Polycystic ovary syndrome. N Engl J Med 1995;333:853-61.

3 Homburg R. What is polycystic ovarian syndrome? A proposal for a consensus on the definition and diagnosis of polycystic ovarian syndrome. Hum Reprod 2002;17:2495-9.

4 Dunaif A, Segal KR, Futterweit W, Dobrjansky A. Profound peripheral insulin resistance, independent of obesity, in polycystic ovary syndrome. Diabetes 1989:38:1165-74.

5 O'Meara NM, Blackman JD, Ehrmann DA, Barnes RB, Jaspan JB, Rosenfield RL, et al. Defects in beta-cell function in functional ovarian hyperandrogenism.J Clin Endocrinol Metab 1993;76:1241-7.

6 Barbieri RL. Hyperandrogenism, insulin resistance and acanthosis nigricans. 10 years of progress. J Reprod Med 1994;39:327-36.

7 Dunaif A. Insulin resistance and the polycystic ovary syndrome: mechanism and implications for pathogenesis. Endocr Rev 1997;18:774-800.

8 Nestler JE. Insulin regulation of human ovarian androgens. Hum Reprod 1997;12(suppl 1):53-62.

9 Practice Committee of the American Society for Reproductive Medicine. Use of clomiphene citrate in women. Fertil Steril 2003;80:1302-8.

10 Imani B, Eijkemans MJ, te Velde ER, Habbema JD, Fauser BC. A nomogram to predict the probability of live birth after clomiphene citrate induction of ovulation in no probability of live birth after clomiphene citrate induction of on

11 Nestler JE, Barlascini CO, Matt DW, Steingold KA, Plymate SR, Clore JN, et al. Suppression of serum insulin by diazoxide reduces serum testosterone levels in obese women with polycystic ovary syndrome. J Clin Endocrinol Metab 1989;68:1027-32.

12 Velazquez EM, Mendoza S, Hamer T, Sosa F, Glueck CJ. Metformin therapy in polycystic ovary syndrome reduces hyperinsulinemia, insulin resistance, hyperandrogenemia, and systolic blood pressure, while facilitating normal menses and pregnancy. Metabolism 1994;43:647-54.

13 Nestler JE, Jakubowicz DJ. Decreases in ovarian cytochrome P450c17 alpha activity and serum free testosterone after reduction of insulin secretion in polycystic ovary syndrome. N Engl J Med 1996;335:617-23.

14 Nestler JE, Jakubowicz DJ, Evans WS, Pasquali R. Effects of metformin on spontaneous and clomiphene-induced ovulation in the polycystic ovary syndrome. $N$ Engl J Med and clomiphene-ind $1998 ; 338: 1876-80$.

15 El-Biely MM, Habba M. The use of metformin to augment the induction of ovulation in obese infertile patients with polycystic ovary syndrome. Middle East Fertility Society Journal 2001;6:43-9.

16 Garber AJ, Duncan TG, Goodman AM, Mills DJ, RohlfJL. Efficacy of metformin in type II diabetes: results of a double-blind, placebo-controlled, dose-response trial. Am J Med 1997;103:491-7.

17 Eijkemans MJ, Imani B, Mulders AG, Habbema JD, Fauser BC. High singleton live birth rate following classical ovulation induction in normogonadotrophic anovulatory infertility (WHO 2). Hum Reprod 2003;18:2357-62.

18 Lord JM, Flight IH, Norman RJ. Insulin-sensitising drugs (metformin, troglitazone, rosiglitazone, pioglitazone, D-chiro-inositol) for polycystic ovary syndrome. Cochrane Database Syst Rev 2003;(3):CD003053.
19 Glueck CJ, Phillips H, Cameron D, Sieve-Smith L, Wang P. Continuing metformin throughout pregnancy in women with polycystic ovary syndrome appears to safely reduce first-trimester spontaneous abortion: a pilot study. Fertil Steril 2001;75:46-52

20 Jakubowicz DJ, Iuorno MJ, Jakubowicz S, Roberts KA, Nestler JE. Effects of metformin on early pregnancy loss in the polycystic ovary syndrome. J Clin Endocrinol Metab 2002;87:524-9.

21 Heard MJ, Pierce A, Carson SA, Buster JE. Pregnancies following use of metformin for ovulation induction in patients with polycystic ovary syndrome. Fertil Steril 2002;77:669-73

22 Wilcox AJ, Weinberg CR, O'Connor JF, Baird DD, Schlatterer JP, Canfield RE, et al. Incidence of early loss of pregnancy. N Engl J Med 1988;319:189-94.

23 Regan L, Braude PR, Trembath PL. Influence of past reproductive performance on risk of spontaneous abortion. BMJ PL. Influence of

24 Alberman E. Spontaneous abortion: epidemiology. In: Stabile S, Grudzinkas G, Chard $\mathrm{T}$, eds. Spontaneous abortion: diagnosis and treatment. London: Springer-Verlag, 1992:9-20.

(Accepted 28 March 2006)

doi $10.1136 /$ bmj. 38867.631551 .55

Centre for Reproductive Medicine, Department of Obstetrics and Gynaecology, Academic Medical Centre, PO Box 22700, 1100 DE, Amsterdam, Netherlands

Etelka Moll registrar obstetrics and gynaecology

Fulco van der Veen professor in reproductive medicine

Clinical Epidemiology and Biostatistics, Academic Medical Centre, Amsterdam, Netherlands

Patrick M M Bossuyt professor in clinical epidemiology

Johanna C Korevaar clinical epidemiologist

Division of Reproductive Medicine, Department of Obstetrics and Gynaecology, Vrije Universiteit Medical Centre, PO Box 7057, 1007 MB, Amsterdam, Netherlands

Cornelis B Lambalk gynaecologist

Correspondence to: E Moll e.moll@amc.uva.nl

\section{Amendment}

This is version 2 of the paper. In this version the trial registration number has been corrected as there was a missing digit in the first version. 